\title{
Satish Dhawan: Visionary, humanitarian and unparalleled administrator
}

\author{
B. L. Deekshatulu* \\ Distinguished Fellow, Institute for Development and Research in Banking Technology (RBI-Government of India), Hyderabad 500 057, India
}

SEVERAL moons back, a thief while jumping over a boundary wall, got injured. The family residing in the house promptly came out upon hearing the loud noise from the fall. While they were enraged and scared at the attempted robbery, the owner of the house took an unusual decision. At 2 a.m., he helped the rogue into his car and personally drove him to a hospital. While the doctors nursed the robber's wounds, the owner left him with words of wisdom and life lessons on never to steal for a living.

The man was none other than Satish Dhawan, a genius and founding father of the Indian Space Research Organisation (ISRO), who shaped it into an elite institution and pioneer space research organization in the world.

Despite his achievements, authority and influence, Dhawan embodied simplicity, humanity and humility in every sphere of his life. As one of the fortunate few to be closely associated with him since 1962, both at the Indian Institute of Science (IISc), Bangalore and subsequently at ISRO, it is an honour and a great pleasure to reminisce and share some of my memorable experiences from the glorious years that I spent with this legend, each of which has left a lasting impression on me.

\section{Dhawan - The visionary leader}

At age 42, Dhawan became the youngest director to be appointed at IISc. He also remained its longest-serving and most distinguished director (1962-81). As director, Dhawan ushered in several innovative changes in the functioning and administration of IISc. He appointed about 70 new faculty in 1970 in order to infuse fresh blood. Following a suggestion from a Professor in a Senate meeting, he pushed through and ensured the abolition of the then existing, archaic practice of putting fingerprints of all employees in their appointment Register book. Additionally, this Professor also pointed out that the structure of each Department was like a pyramid, with the Department Head at the top, few Assistant Professors and a few Lecturers. With the addition of new, mostly senior faculty, the structure was like an inverted pyramid. An inverted pyramid can only be stable when it is in a state of rotation, like a spinning top. Recognizing the truth in this statement, Dhawan decided to appoint a

\footnotetext{
*e-mail: deekshatulu@hotmail.com
}

rotating Committee of Professors (COP) for each department to ensure decentralized governance.

As Director, Dhawan enjoyed visiting the various Departments regularly and interacting with the faculty and students in each department. He initiated the construction of a Class Room Complex, where faculty and students from all departments could conduct and attend classes, thus fostering multi-disciplinary interactions among students and faculty from various disciplines. Dhawan introduced the maintenance of a Medical Diary at the Health Centre and commenced the construction of many key administrative buildings at IISc, such as the Central Library, Office Complex, Faculty Quarters, all of which are still in use till this day.

Under the leadership of Dhawan and H. N. Ramachander Rao, Head, Department of Electrical Engineering (EE), we were able to start a new ME degree programme in Applied Electronics and Servomechanisms in 1963. We also started many new courses under this stream such as adaptive control, optimal control, multivariable systems, bio control systems, etc. With the support of Dhawan, we were able to conduct guest lectures for many of these courses by inviting experts from external institutions and from other Departments within IISc. I cite this as one example of the many times we received significant encouragement from Dhawan towards diversification, expansion and promotion of inter-departmental cooperation to improve the quality of education at IISc.

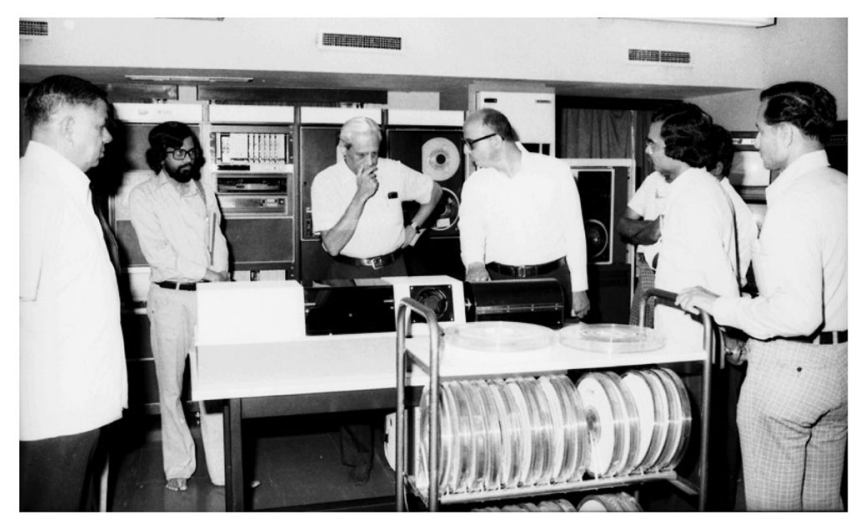

Drum scanner for scanning satellite images was developed to be a pioneering achievement for NRSA in technology development and transfer. Dhawan took keen interest in the development of the scanner and complimented the team. 


\section{SATISH DHAWAN BIRTH CENTENARY}

During the creation of the School of Automation at IISc (later renamed Computer Science and Automation, CSA), with collaboration and assistance from the then USSR, Dhawan, two Professors from Departments of EE and Electrical Communication Engineering and myself, an Assistant Professor at that time, visited USSR in October 1968 for four days. It is worth mentioning here, an example of Dhawan's modesty and down to earth nature. On the third day of our stay in Moscow, after discussions that ran late into the evening, we decided that we should be ready by 7 a.m. for the meetings next day before departing Moscow for India. I suggested to Dhawan that I will wake him up at 5 a.m. to which he replied 'No, I will give you a ring at 5 a.m.', which he absolutely did.

I was in Yorktown Heights, New York, USA working as a Visiting Scientist at IBM during 1971-72. At that time, Dhawan, who was at Caltech, USA working as a Visiting Professor, was asked by the then Prime Minister of India Indira Gandhi to come back to the country as Secretary of a new Government Department, viz. the Department of Space (DoS). Dhawan mentioned this to me at least twice during our phone conversations. I was pleasantly surprised at his candid talk without any airs, since I was then only a Professor at IISc while he, on the other hand, was being asked to join as Chairman ISRO and Secretary DoS. This is yet another example of the humility and friendliness of the person.

After returning from IBM in 1972, USA, I wanted to work in the area of digital image processing, an upcoming area at IISc. With encouragement from Dhawan and Ramachander Rao, my team and I built a drum scanner using an old discarded lathe machine in the workshop premises. Dark room conditions were met using a large tarpaulin cloth draped over the machine and operating the scanner during night only. One had to bend and get under the tarpaulin cover to work on the scanner. Dhawan took keen interest in my work and went through lot of pain to see this innovatively built scanner/imager. Moreover, he would bring along dignitaries visiting IISc during that period, such as M. G. K. Menon (Head of ISRO) and B. D. S. Nag Choudhuri (Member, Planning Commission) to

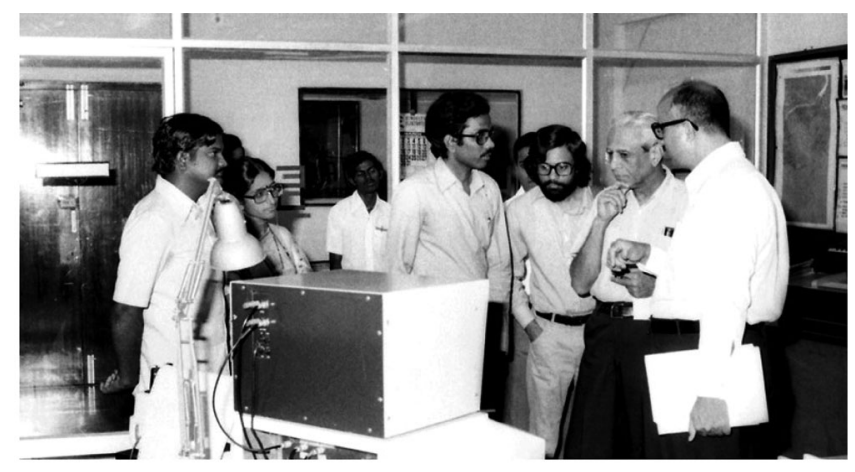

At the Satellite Image Processing Unit built in NRSA. name a few. We all rejoiced these occasions tremendously. Later, a colour drum scanner was also built under an ISRO-funded project.

With a vision towards promotion of remote sensing through aerial surveys, Dhawan recommended we use the then, mostly underutilized, Pushpak aircraft at IISc, after conducting the necessary modifications and retrofitting with multispectral cameras, obtaining DGCA clearances, etc. An aircraft engineer and scientist, Damania, known to Dhawan in the Department of Aeronautics helped in this endeavour. We could perform numerous aerial surveys over nearby places like the citrus plantation in Gonikoppal and sandalwood plantation at Bannerghatta. We engaged in many interactions with scientists at the University of Agricultural Sciences, State Horticulture Department etc. This being the first time, all of us were excited at the results of photo interpretations. With the help of SAC scientists, we could also identify crop yield estimates and diseased crop areas.

With the introduction of courses in remote sensing, digital image processing, pattern recognition, etc. at the master's level, combined with the ability to conduct aerial surveys and commensurate photo processing facilities at the EE Department, IISc soon became the leading academic institution for conducting remote sensing research in India.

I left IISc in 1976 and joined the National Remote Sensing Agency (NRSA) as Head, Technical Division (now called National Remote Sensing Centre (NRSC), an ISRO Centre). NRSA was an autonomous organization under Department of Science and Technology (DST) until 1980, after which it was transferred to DoS. Dhawan was the Secretary of DoS since 1972, and became Chairman of NRSA in 1981 (until 1984). When I became Director of NRSA in 1982, with the support of Dhawan, I was given the responsibility of promoting remote sensing

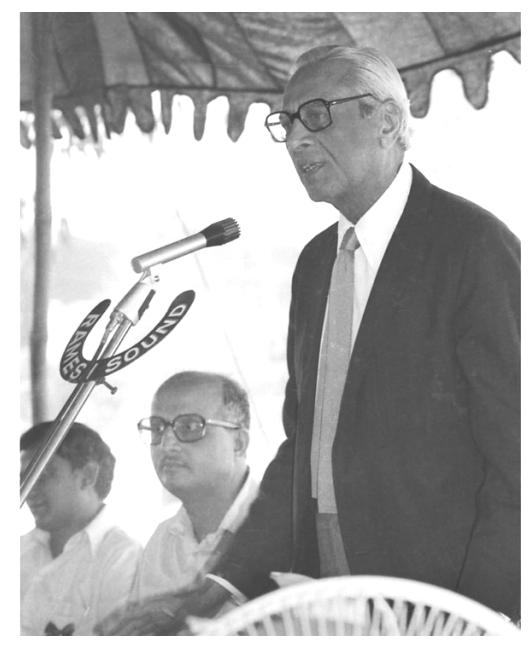

Dhawan was sensitive to the welfare of the employees. During a visit to NRSA in 1983, he declared the introduction of transport facilities for the employees, which was greatly appreciated by them. 
in India (under the aegis of DoS/ISRO) in various sectors such as agriculture and soil, forestry, urban development, oceanography, geology, land development, etc. in addition to promoting remote sensing education and training at the Central and State Government levels.

In 1983, Dhawan proposed that NRSA use remote sensing technology to estimate the forest cover of India and the amount of deforestation. Accordingly, in approximately six months the entire forest cover of the country was estimated under different categories such as closed, open/degraded and mangroves. This was the first ever nationwide forest cover mapping undertaken using scientific methods. Dhawan always felt that there should be independent forest monitoring at regular intervals. $\mathrm{He}$ ensured that the technique of forest mapping was institutionalized within the Forest Survey of India (FSI). He also worked hard to ensure that there was open dialogue with respect to the methodology, discrepancies for reconciliation and institutionalization. Since then, FSI has been using remote sensing technology towards estimating the forest cover of India.

Dhawan took keen interest in promoting and ensuring that remote sensing be applied to and made available at the grass-root level, i.e. at the farmer's and fisherman's level. Later, over the years, numerous nationwide remote sensing projects were executed, e.g. land use planning, wasteland mapping, groundwater mapping, etc. at various scales. These maps, so generated were given to each state authority for use in informing and implementation of state-level projects/policies. In 1982, a national committee, viz. NNRMS (National Natural Resources Management System) of ISRO was in place. The progress on the use of remote sensing was regularly reviewed by NNRMS consisting of various user Department Secretaries.

With the launch of IRS satellite series by ISRO in 1988, satellite-based remote sensing technology and data have been widely used for tackling various civic and societal applications across India. Here too, Dhawan had the foresight to introduce the then novel satellite-based remote sensing technology at the school and college level in India, to ensure rapid growth and adoption of the technology. To this end, many meetings were held with the University Grants Commission (UGC) and other officials (Manmohan Singh was the Vice Chairman of UGC then). Letters were sent from UGC to all universities nationwide to introduce (in whichever reasonable way), new courses on satellite remote sensing and its applications. Since then, we have seen how different universities/colleges in India have adopted this new technology in their curriculum. Similar efforts were made to introduce remote sensing concepts at the school level.

The (former) Indian Photo Interpretation Institute (IPI) at Dehradun, under NRSA, was completely transformed into a modern training and research Institute in Remote Sensing (now the Indian Institute of Remote Sensing,
IIRS), with major emphasis on satellite technology and projects. Dhawan was the force behind this transformation. Due to its elevated status, IIRS was recognized to house the UN's Institute CSSTEAP in 1995, for which I was appointed as the first Director. With support from Dhawan and subsequent Secretaries of DoS, CSSTEAP has become a role model for remote sensing education in the Asia-Pacific region.

Since the inception of NRSA (as an autonomous body under DST), the Director of NRSA had the administrative and financial authority to send any NRSA personnel abroad on official work. After NRSA was absorbed under the DoS in December 1980, given that no Centre Director within ISRO had such authority, I brought this point to the attention of Chairman Dhawan. He immediately said, 'Yes I know, you have these powers, what is there!' Such was the magnanimity of this man. This privilege continued for the Director of NRSA until his Chairmanship ended.

\section{Dhawan - an honorable human}

Dhawan was a great scientist, leader and administrator. He had the unique combination of understanding any scientific or technological problem, analysing and finding its applications to the masses. In my numerous discussions with him for over 40 years, I could always see the transparency of the person, his thoughts, simplicity, frank discussions and most importantly - his complete lack of ego. I had the freedom to tell him whatever I did not like. He was affectionate and sensitive to the needs of others. He would always look out for the welfare of others, especially people who possessed merit but were timid (not flashy), and those who needed a helping hand. I was privileged to witness many incidents over the years that showcased these character traits of Dhawan and have left a lasting impression on me.

Once Dhawan, Menon (whom Dhawan affectionately called as 'Goku') and myself were on a tour and stopped by a wayside/countryside tea stall. As the tea was being made, Dhawan spelt out his appreciation of the effort put in by the vendor; from the method of cleaning the glasses to making fresh tea (not utilizing the leftover tea in the pot), the care taken to serve, etc. I realized then that some great people like Dhawan also observe and take keen interest in minor matters of all sections of the society.

Dhawan was concerned with the career growth of every employee. In traditional Government departments, promotion was based purely on seniority and vacancy. He introduced a scheme called 'Flexible Complementing', in which promotions were based on merit and work output and did not depend on vacancies. When an employee gets promoted to a higher grade, a notional post at the higher level gets created automatically. When he leaves that post 
the vacancy arises at the bottom level, that is, to the originally sanctioned post.

Dhawan also introduced a scheme called 'Category Change', wherein a helper can become a technician provided he has acquired the necessary skills while in service and clears the rigorous tests.

On several occasions Dhawan, the Registrar and one or two IISc staff, including myself, used to hire a taxi from Delhi airport and get dropped at our respective places of stay in Delhi. While in the taxi, Dhawan, the ever thoughtful person, used to tell the Registrar 'See that the last person does not end up paying the taxi bill'. I was astonished at his eye for detail.

Once during a COP meeting at the School of Automation, IISc, we had reached an impasse following numerous differences of opinions and the committee members decided to present our differing views, grievances, etc. to Director Dhawan. He patiently listened to all our complaints and when we finally paused, asked, 'Is there at least one thing in the Institute that is working well?' This statement put all of us to shame, making us feel ashamed at our pettiness and not having appreciation for the excellent institution we were all working for.

Dhawan's complete lack of parochialism is unparalleled. His tendency to take the blame in times of crisis, but give full credit to others at times of success is legendary across the DoS. Dhawan fostered a management style in ISRO that encouraged even junior employees to speak up in meetings. This style of management helped ISRO immensely in identifying and nurturing talent, and ensured that even people at higher levels would have to answer any question in committees. The administrative reforms that Dhawan instituted along with T. N. Seshan (the then Additional Secretary of DoS) are worth remembering. He instituted employee-side consultative mechanisms that effectively minimized any strikes, etc. even in a state like Kerala. Also, his insistence on retaining the ISRO Headquarters in Bangalore and not in Delhi ensured that DoS was not encumbered by any potential bureaucracy.
Discussions with Dhawan on any point or problem were always grounded on two things; the big picture, nation development, etc. and the immediate actions that needed to be taken to achieve the objective. He pushed us to be effective and always keep the needs of the nation in our mind when working on any problem. He was particular that the Indian space programme be entirely focused towards peaceful applications. During his tenure, Dhawan never allowed any defence use of our space programme. This peaceful nature of ISRO probably helped DoS get international support for its work and also escape potential sanctions.

Dhawan was always prepared to take up cudgels whenever he felt that a wrong had been done. In the well-known ISRO espionage case when there was an attempt to reopen it after Nambi Narayanan was acquitted, Dhawan along with some other prominent scientists wrote an open letter to the Prime Minister. I think these attempts eventually helped and finally, Narayanan was completely cleared of the charges, given a cash compensation and conferred with the Padma Bhushan Award in 2019.

A meticulous man of perfection, Dhawan would explain how power-point presentations should be made, how many lines should there be in a slide and how long each slide should be shown. An extremely humble man, he did not like to be praised nor talk bad about another person, especially behind his back. His eloquence in English, his ability to always see the big picture, giving everyone complete freedom in any matter, all make Dhawan truly the only one of his kind. The legacy of Dhawan's words continue in ISRO's progress and achievements:

'If you do not have a mission no problem will occur, but if you do have a mission or task, definitely problems of varying magnitude will crop up. But problems should not become the master of the individual, the individual should become the master of the problem, defeat it and succeed.'

doi: $10.18520 / \mathrm{cs} / \mathrm{v} 119 / \mathrm{i} 9 / 1440-1443$ 